2019-05

\title{
Anthropogenic noise pollution reverses grouping behaviour in hermit crabs
}

Tidau, Svenja

http://hdl.handle.net/10026.1/14367

10.1016/j.anbehav.2019.03.010

Animal Behaviour

Elsevier Masson

All content in PEARL is protected by copyright law. Author manuscripts are made available in accordance with publisher policies. Please cite only the published version using the details provided on the item record or document. In the absence of an open licence (e.g. Creative Commons), permissions for further reuse of content should be sought from the publisher or author. 


\section{Anthropogenic noise pollution reverses grouping behaviour 2 in hermit crabs}

\section{Abstract}

Mark Briffa
This is a final accepted manuscript. The definitive version of this study is at Animal Behaviour https://doi.org/10.1016/j.anbehav.2019.03.010

Svenja Tidau (corresponding author)

Noise is a form of human induced rapid environmental change, and mounting evidence suggests that it can affect the sensory environment and consequently the decision-making ability of animals. However, while the effects of anthropogenic noise on individual organisms in the context of movement patterns, foraging and predator risk have been reported, relatively little is known about how noise impacts groups and intraspecific interactions. Here we investigated the effects of anthropogenic noise on grouping preference (i.e. being with conspecifics or alone) in the European hermit crab, Pagurus bernhardus. Hermit crabs live in empty gastropod shells and frequently fight with each other in order to gain an optimal-fitting shell. Thus crab grouping preference may depend on the optimality of their own shell and thus on their motivation to gain another. In order to test the effect of shell size and its interaction with noise exposure on grouping preferences, crabs were housed in either suboptimal or optimal shells before being exposed to playbacks of either ship noise or an ambient sound (control) and given the choice to group with either five crabs, one conspecific or to remain alone in a neutral zone. Crabs occupying suboptimal shells displayed a longer latency to 
enter the zone with a single crab than crabs in optimal shells. This difference was only seen in the ambient sound treatment, disappearing completely under ship noise. Under ambient sound, crabs in optimal shells spent most of their time close to a single crab, while crabs in suboptimal shells showed no clear preference. However, exposure to ship noise reversed the effect of shell quality on grouping preference. Our results demonstrate that exposure to anthropogenic noise can not only alter individual behaviour but also social behaviour.

Keywords: anthropogenic noise, environmental change, grouping preference, hermit crabs, intraspecific interaction, sensory environment

\section{Introduction}

Assessing diverse cues from the environment is an essential component of animals' decision-making. However, human induced rapid environmental change (HIREC) (sensu Sih, Ferrari \& Harris, 2011), caused by noise, chemicals or light, can disrupt information gathering, processing and assessment in animals both by inducing physiological stress (for review see Kight \& Swaddle, 2011) and by changing animals' sensory environment (for review see Halfwerk \& Slabbekoorn, 2015; Tuomainen \& Candolin, 2011). An example of unimodal interference by noise is the masking of acoustic cues and signals documented in terrestrial and aquatic taxa (Brumm, 2004; Clark et al., 2009; Luo, Siemers \& Koselj, 2015; Simpson et al., 2016a; Sun \& Narins, 2005;). This has been demonstrated across behavioural contexts such as territory defence (Brumm, 2004), mating (Sun \& Narins, 2005) and the detection of habitats (Pine, Jeffs \& Radford, 2012), conspecifics (Codarin, Wysocki, Ladich \& Picciulin, 2009) and predators (Curé et al., 2013). In addition to these unimodal effects, noise can also have cross-modal effects where this pollutant disrupts information processing and assessment of nonacoustic cues (Halfwerk \& Slabbekoorn, 2015). For instance, underwater noise has been shown to 
alter behaviours related to visual and chemical cues used in predator avoidance and detection (Hasan, Crane, Ferrari \& Chivers, 2018; Kunc, Lyons, Sigwart, McLaughlin \& Houghton, 2014; McCormick, Allan, Harding \& Simpson, 2018). Such effects have been explained by distraction (Chan, Giraldo-Perez, Smith \& Blumstein, 2010) due to limited attention in animals (Dukas, 2004), which modulates the multisensory integration (Talsma, Senkowski, Soto-Faraco \& Woldorff, 2010). This effect has also been termed 'info-disruption' (Lürling \& Scheffer, 2007) and 'sensory pollution' (Halfwerk \& Slabbekoorn, 2015). In addition to these sensory effects noise has been shown to cause physiological stress (for review see Kight \& Swaddle, 2011), which could also alter animal behaviour. Cross-modal noise pollution might therefore adversely affect animals even though they do not use acoustic communication.

The behavioural effects of anthropogenic noise have frequently been studied in two contexts. First, many studies have focussed on individual behaviour, including impacts on movement, foraging and responses to predators (Chan et al., 2010; Luo et al., 2015; Shafiei Sabet, Neo \& Slabbekoorn, 2015; Shafiei Sabet, Dooren \& Slabbekoorn, 2016; Shannon et al., 2016; Siemers \& Schaub, 2011; Simpson, Purser \& Radford, 2015; Simpson et al., 2016b; Wale, Simpson \& Radford, 2013; Wisniewska et al., 2018). Second, studies on social behaviour have focussed on the potential masking of acoustic communication in insects, anurans, birds, and mammals (reviewed in Brumm \& Slabbekoorn, 2005; Erbe, Reichmuth, Cunningham, Lucke \& Dooling, 2016). In contrast, the effect of noise on non-vocal social behaviour, such as shoaling, has received relatively little attention. Those noise exposure experiments which studied intraspecific interactions found altered parental care (Maxwell et al., 2018; Nedelec et al., 2017) and social interactions (Bas et al., 2017). A basic aspect of social behaviour is that individuals choose to join groups such as flocks or shoals, which requires animals to assess cues from their environment. Groups are associated with a range of benefits (reviewed in Krause \& Ruxton, 2002) such as decreased vigilance (Powell, 1974; Ward, Herbert-Read, Sumpter \& Krause, 2011), finding and exploiting resources (Bazazi, Pfennig, Handegard \& Couzin, 
there are also costs associated with group membership such as increased attack rates (for large groups) (Mooring, Fitzpatrick, Nishihira, Reisig \& Hall, 2004), elevated parasite burden (Côté \& Poulinb, 1995; Daviews, Ayres, Dye \& Deane, 1991) and foraging competition (Rieucau \& Giraldeau, 2009). Noise has been shown to alter grouping (Fewtrell \& McCauley, 2012; Herbert-Read, Kremer, Bruintjes, Radford \& loannou, 2017) and appears to be highly variable across study systems and noise regime. Mediterranean spiny lobster, Palinurus elepha, (Filiciotto et al., 2014) and bottlenose dolphin, Tursiops truncatus, (Bas et al., 2017) exhibited reduced grouping behaviour when exposed to boat noise. In contrast noise led to increased grouping in the trevally, Pseudocaranx dentex, (Fewtrell \& McCauley, 2012). Divergent social responses to noise can even be seen within the same species. In the European sea bass, Dicentrarchus labrax, the social behaviour differed with the noise source and regime where fish shoals were less coordinated (cohesion, direction, speed and directional changes) when exposed to pile-driving (Herbert-Read et al., 2017) but they increased grouping activities under ship noise (Neo, Hubert, Bolle, Winter \& Slabbekoorn, 2018). In the Atlantic bluefin tuna, Thunnus thynnus, noise led to less concentrated and coordinated shoals but individuals increasingly swam towards one and another and seemed more likely to join a group (Sara et al., 2007). Although less intensively studied (compared to aquatic examples) anthropogenic noise can also affect non-vocal social behaviour in terrestrial species. In Carolina chickadees, Poecilie carolinensis, and tufted titmice, Baeolophus bicolor, flocking density was enhanced in the presence of traffic noise (Owens, Stec \& O'Hatnick, 2012). Thus, as well as changing the propensity to join groups, noise can influence interactions within groups.

In marine environments, grouping is very common among cetaceans and fish (i.e. shoaling) but has also been demonstrated in crustaceans as a response to predation risk (Evans, Finnie \& Manica, 2007; Ratchford \& Eggleston, 1998). Due to their association with gastropod shells hermit crabs represent an ideal model organism for studying the effects of underwater noise on the drivers of grouping behaviour. They are globally distributed crustaceans characterised by a weakly calcified abdomen which they protect from predators (Vance, 1972) and environmental extremes (Taylor, 
1981; Young, 1978) through occupying empty gastropod shells. They usually obtain these either when discarded by others or through shell fights with other crabs (snail predation is rare) (Elwood \& Neil, 1992). Hermit crabs need to search for empty shells of increasing size to allow for growth or, in the case of females, during the reproductive season to accommodate their eggs (Angel, 2000; Bertness, 1981a). The extent of grouping in hermit crabs differs between species, from those which are solitary (Hazlett, 1979) to those which form aggregations of hundreds or even thousands of individuals as in Clibananus erythropus (Gherardi, 1991). The drivers for grouping can differ widely between species. These include attraction to foraging sites (Hazlett, 1979; Hazlett, 2015), shell exchange (Gherardi \& Vannini, 1993; Hazlett, 1978; Hazlett \& Herrnkind, 1980) and predator defence (Bertness, 1981b). The need to obtain new shells could also influence grouping. Shell exchange markets as observed in the mangal-dwelling hermit, Clibanarius laevimanus, and the thin stripe hermit crab, Clibanarius vittatus, (Gherardi \& Vannini, 1993; Hazlett \& Herrnkind, 1980), and vacancy chain processes in the European hermit crab, Pagurus bernhardus, (Briffa, 2013), predict that associating with other crabs may increase the chances of finding an optimal shell (Gherardi \& Vannini, 1993). In addition, the larger the group the lower the likelihood at the individual-level of being preyed upon, an effect known as the dilution effect (Foster \& Treherne, 1981; Gherardi \& Benvenuto, 2001). On the other hand, larger groups can be more detectable (Krause \& Ruxton, 2002) and for hermit crabs their individual defence mechanisms, primarily withdrawing into their gastropod shell (Gherardi \& Benvenuto, 2001) or fleeing (Mima, Wada \& Goshima, 2003; Rosen, Schwarz \& Palmer, 2009; Scarratt \& Godin, 1992), might be a better responses to a predator attack compared with joining a group. Given this array of the potential costs and benefits of grouping, to make decisions on whether to join a group hermit crabs need to assess information from their environment across different sensory modalities, including tactile information on the size of the shell relative to their own size (smaller shells offer less protection).

As in other hermit crabs $P$. bernhardus are frequently found in aggregations, and the factors described above are all likely to contribute to this (Elwood \& Neil, 1992). Here we aim to determine 
whether the decision to join a group in the European hermit crab $P$. bernhardus is influenced by

127

information on risk level (i.e. shell fit) and information on the number of conspecifics in a group. We then ask whether the grouping patterns are altered in the presence of anthropogenic noise using ship noise playbacks and ambient controls. We predict that, due to a combination of shell exchange markets and the dilution effect, crabs in suboptimal shells are more likely to join a group compared to crabs in optimal sized shells. Furthermore, if noise distracts hermit crabs and reduces their ability to use information on shell and group size, we expect these different grouping preferences of crabs in suboptimal and optimal shells (described above) to be altered by noise.

\section{Methods}

\section{Collection and husbandry of hermit crabs}

We collected $P$. bernhardus from the rocky intertidal of Hannafore Point, Cornwall, UK $\left(50^{\circ} 20 \mathrm{~N}, 4^{\circ} 27 \mathrm{~W}\right)$ in May and July 2017 and transported them directly to the laboratory at the University of Plymouth, UK. We kept the crabs in a temperature controlled room at $15^{\circ} \mathrm{C}$ with a 12:12 hour light:dark cycle in a single holding tank containing 125 I continuously filtered and aerated seawater (Briffa, Rundle \& Fryer, 2008). The laboratory seawater was obtained from the seaward side of Mount Batten pier $\left(50^{\circ} 36 \mathrm{~N}, 4^{\circ} 13 \mathrm{~W}\right)$ in Plymouth Sound, UK, at spring tides. We fed crabs ad libitum with white fish. To remove focal crabs from their original gastropod shells (at least 22 hours prior to observations) we carefully cracked the shell with a bench vice, which allows the crab to be removed from its shell without injuring the crab. Afterwards the crabs were sexed and weighed them. The crab mass ranged from $0.36 \mathrm{~g}$ to $1.61 \mathrm{~g}$ (mean mass $\pm \mathrm{SE}=0.84 \mathrm{~g} \pm 0.045 \mathrm{~g}, N=45$ ). Based on a regression line relating preferred shell mass to body mass obtained from a previous shell selection experiment, where crabs across a range of sizes were provided with free access to a range of different sized shells (Briffa \& Elwood, 2007), we assigned a Littorina littorea shell of either $75 \%$ or $100 \%$ of its preferred shell mass to each crab. Although a range of other shell features might also influence preferences, the relation between crab mass and shell mass is the primary predictor of shell preference. To optimise the reliability, the shell selection experiment (Briffa \& Elwood, 2007) 
was conducted using shells collected from the same location as the hermit crabs used in this study to minimise the effect of factors such as shell internal volume to weight ratio, which can differ between study sites. Furthermore, following a standard approach, only clean and intact shells, without encrusting organisms, holes or damage to the aperture were used. Afterwards we housed crabs individually in a white plastic dish of $15 \mathrm{~cm}$ diameter containing continuously aerated seawater to a depth of $5 \mathrm{~cm}$. Since the breeding season is likely to affect the behaviour of egg-carrying females, we used only male crabs without obviously damaged appendages, visible parasites or recent moult (Briffa \& Elwood, 2007). After the observations we returned the animals to the sea at the collection point.

\section{Tank set-up and sound analysis} aquarium glass) filled to a depth of $40 \mathrm{~cm}$ with seawater from the laboratory supply ( $160 \mathrm{I}$ ). We

We carried out the observations in a $80 \times 50 \times 50 \mathrm{~cm}$ sized glass tank (with $1 \mathrm{~cm}$ thick placed the tank on a free-standing trolley and cushioned the set-up with $1 \mathrm{~cm}$ Styrofoam plates between tank and trolley as well as between the trolley and floor. We suspended an underwater speaker from a cushioned bamboo stick at $20 \mathrm{~cm}$ distance to one end of the tank, facing towards an observation arena (Fig. 1). At $10 \mathrm{~cm}$ distance to the speaker we divided the observation arena $(50 \mathrm{~cm}$ width $\times 40 \mathrm{~cm}$ length) from the rest of the tank with $1 \times 1 \mathrm{~cm}$ mesh. Along either side of the glass walls we separated two 'stimulus chambers ( $6 \mathrm{~cm}$ width) for the two groups of stimulus crabs (see details below). The chambers were custom-made of $3 \mathrm{~mm}$ transparent acrylic sheets. Adjacent to each of these stimulus chambers, we defined 'decision zones' (9 $\mathrm{cm}$ in width) marked by a line on the base of the arena so that the focal crab could enter freely into either decision zone. We designated a 'neutral zone' (18 cm width) at the centre of the tank. At the beginning of each observation, we placed the focal crabs in the centre of the neutral zone at $30 \mathrm{~cm}$ distance from the speaker and equal distance to the walls of the stimulus chambers. At this location (point in Fig. 1) we analysed the sound pressure levels of the two sound treatments (ship noise and ambient control). 
While hearing in a narrow definition seems to be absent in nearly all aquatic crustaceans, sound detection has been widely demonstrated in Decapoda (Budelmann, 1992). Only very few auditory thresholds have been established for invertebrates but an experiment the common prawn, Palaemon serratus, showed an auditory brain response to acoustics stimuli at a frequency range of 100-3000 Hz with amplitudes varying between 105 and $130 \mathrm{~dB}$ RMS re $1 \mu$ Pa at $1 \mathrm{~m}$ (Lovell, Findlay, Moate \& Yan, 2005). There has been no similar study conducted for $P$. bernhardus but behavioural sensitivity (antennae flicks) to substrate borne vibration in this species has been demonstrated for frequencies between $5-410 \mathrm{~Hz}$ at a particle acceleration of 0.02-0.44 $\mathrm{ms}^{-2} \mathrm{RMS}$ (Roberts, Cheesman, Elliott, \& Breithaupt, 2016).

For the sound playbacks we used an underwater speaker (DNH Aqua-30 underwater speaker, effective frequency range $80-20000 \mathrm{~Hz}, \mathrm{DNH} A / \mathrm{S}$, Kragerø, Norway) connected to a Lvpin LP-200 amplifier (Lvpin Technology Suzhou Co., Taiping Town, China). We played back the sound tracks from a Toshiba Portégé R830-13C laptop (Tokyo, Japan). For the sound treatment we used three ship noise playbacks and three corresponding ambient control sounds from the same sites recorded at three major UK harbours (for details on recordings such as ship size and speed see Simpson et al., 2015; Wale et al., 2013). We used Audacity 2.1.2 (Audacity Team, 2017) to create a total of six audio tracks. In the case of ship noise tracks we alternated two min of ship noise with two min of ambient control sound including $15 \mathrm{sec}$ fading in and out to simulate noise of passing by ships. We assigned the crabs randomly to one of the two sound treatments (ambient, ship) and to one of the alternative three audio tracks within these sound treatments (ambient A, B, C; ship A, B, C) and alternated the sound treatment between subsequent observations.

To make sure crabs were exposed to two distinct sound treatments we analysed the power spectrum as a proxy similar as in previous studies on crustaceans (for instance Wale, Simpson \& Radford, 2013). We are aware of the challenges of measuring noise in small tanks (Rogers, Hawkins, Popper, Fay \& Gray, 2016; Simpson et al., 2015) and that hermit crabs are likely to perceive the particle motion component of sound rather than the measured sound pressure levels (Breithaupt, 
2002; Popper, Salmon \& Horch, 2001). However, as pointed out in previous studies (see for instance Herbert-Read et al., 2017; Simpson et al., 2015; Wale et al., 2013), we do not aim to establish absolute noise sensitivity levels for hermit crabs but analysed the power spectrum to confirm that we exposed crabs to two different sound treatments, namely ship noise and ambient control. To do that, we re-recorded the six audio tracks at the centre of the arena at $30 \mathrm{~cm}$ distance to the speaker and $25 \mathrm{~cm}$ to the glass walls (were the crabs were be placed at the beginning of the experiment) at 1-2 cm distance to the bottom of the tank with an omnidirectional hydrophone HTI-96-MIN (with inbuilt preamplifier, manufacturer-calibrated sensitivity - $165 \mathrm{~dB}$ re $1 \mathrm{~V} \mu \mathrm{Pa}-1$; frequency range 0.002-30 kHz, High Tech Inc., Gulfport, MS, USA) and Linear Sony PCM-M10 recorder (48 kHz sampling rate, Sony Corporation, Tokyo, Japan; recording level calibrated using pure sine wave signals from a function generator with a measured voltage recorded in line on an oscilloscope). At this position, the three ambient control sounds had an average maximum sound pressure level of 74.5 dB RMS re $1 \mu$ Pa (ambient A: 70.8, ambient B: 76.2, ambient C: 76.6) and the ship noise an average maximum of $119.4 \mathrm{~dB}$ RMS re $1 \mu$ Pa (ship A: 124.4 , ship B: 118.7 , ship C: 115.2 ) at $1000 \mathrm{~Hz}$. We used PAMGuide (Merchant et al., 2015) for MATLAB R2015b (MathWorks Inc., 2015) to perform a power spectrum analysis of $60 \mathrm{sec}$ recording with Hann evaluation window, overlap 50\%, $0.25 \mathrm{sec}$ window length, $1-48000 \mathrm{~Hz}$ bandwidth normalised to $1 \mathrm{~Hz}$ (Fig. 2).

\section{Experimental design and behavioural analysis}

We designed a classical choice experiment with three zones (Krause \& Ruxton, 2002) (see

Fig. 1), which has previously been applied on shoaling in crustaceans (Evans, Finnie \& Manica, 2007). Consequently, the observation arena had a neutral zone in the centre $(1 / 2$ of the arena) and two decision zones (each 1/4 of the arena) between the neutral zone and two stimuli chambers for the stimuli crabs. One chamber was the single crab stimulus chamber (SSC) containing one crab and the second chamber was the group stimulus chamber (GSC) containing five stimuli crabs as in a previous study (Evans, Finnie \& Manica, 2007). That led to a neutral zone of $18 \mathrm{~cm}$ width in the centre, surrounded by two decision zones each of $9 \mathrm{~cm}$ width and two stimulus chambers of $6 \mathrm{~cm}$ width 
(plus $1 \mathrm{~cm}$ thick glass tank on either side). In order to remove the possibility of directional bias we alternated the sides of the SSC and GSC between each day of observations. After being placed in a stimulus chambers, we gave the stimulus crabs $20 \mathrm{~min}$ to acclimatise to the tank before any of the six sound tracks was played. We ran the experiment in blocks of observations where the same stimuli crabs (one and five individuals in each observation) were used repeatedly for eight observations of focal individuals (thus an experimental block = eight observations of unique focal crabs per day, reusing the same stimuli crabs across these eight observations). Furthermore, observations within each block consisted of four observations in the presence of ship noise and four observations under ambient control conditions). We matched focal and stimulus crabs for size based on sight as closely as possible. After observations were completed, we removed the stimulus crabs from their shells, sexed and weighed each crab to test the effectiveness of matching focal and stimulus crabs by calculating the relative weight differences between focal and stimulus crabs. The weight of the focal crabs was positively correlated with the weight of SSC crabs (Spearman's rank correlation: $\left.r_{s}=0.67, N=45, P<0.0001\right)$ and the average weight of crabs in the GSC group weight $\left(r_{s}\right.$ $=0.63, N=45, P<0.0001)$. Immediately following the start of the playback, of either ship noise or ambient control, we placed the focal crab in the centre of the neutral zone (equidistant from the boundary of each association zone) and in an inverted position with the aperture of the shell facing upwards. Once the focal crab recovered from the startle response (it emerged from its shell and contacted the bottom of the tank with a walking leg), we recorded its behaviour for 20 min (Canon Legria HF R47 digital video camera; Tokyo, Japan). We assigned focal crabs to be in association with either the single conspecific or the group of five conspecifics when the whole of their occupied shell had crossed the outer boundary of the appropriate decision zone. We excluded crabs that climbed up the mesh and escaped the arena or did not emerge from their shell after five min from the analysis. We coded the behaviour with The Observer version 12 (Noldus IT, Wageningen, the Netherlands) event logger software blind to the sound treatment and the occupied shell size. We recorded whether each decision zone was entered, the latency to enter each decision zone and the 
average proportion of the total observation time spent in each of the three zones. Thus, the experiment contained two factors, sound treatment and shell size, and four treatment combinations (Table 1).

\section{Statistical analysis}

In order to determine whether ship noise and shell size influenced the chance of crabs entering the single and group stimulus zone we used Generalised Linear Mixed Effect Models implemented in the R-package Ime4 (Bates, Mächler, Bolker \& Walker, 2015) in R version 3.3.2 (R Core Team, 2017) with a binary response variable. For the response variable of whether or not crabs entered a zone (yes or no), sound (ambient and noise) and occupied shell (suboptimal $=75 \%$ and optimal $=100 \%$ ) were the fixed factors and body mass was also included as a covariate. In order to account for the repeated use of three different sound playbacks for both sound treatments (noise and ambient) we included playback as a random factor. To account for the fact that each set of stimuli crabs was used for eight observations of focal crabs per day, block was also treated as a random factor. In order to determine the effects of sound treatment and shell size on the latency and average proportion of time spent in each zone, we used linear mixed effect models, again implemented using the Ime4 package. As above, we included playback ID and block of the experiment as random factors. Finally, to determine whether shell size and noise treatment influenced the average proportion of time spent in all three zones, we used a single linear mixed effects model and to account for the fact that we took three measurements from each focal crabs to analyse the average proportion of time spent in each zone (single/neutral/group), we added zone as a fixed factor and the focal crab ID as a third random factor. We used post-hoc residual plots to assess the fit of each model. Where necessary we natural log transformed the data to improve normality, such that the assumption of the linear models would be met. 
Ethical note: No animals were harmed during the experiment. After the experiment each crab was supplied with an optimal shell, fed and returned to the sea at the location of collection. No licences or permits were required for this study.

\section{Results}

There was no interaction between sound treatment and shell size and no main effects of sound treatment, shell size or crab weight on whether crabs entered the single zone (Table 2). Similarly, there was no interaction between sound treatment and shell size and no main effect sound treatment, shell size or crab weight on whether crabs entered the group zone (Table 2).

There was, however, a significant interaction between sound treatment and shell size on the latency to enter the single zone (Table 2, Fig. 3). Under the ambient control treatment, crabs in suboptimal shells showed a longer latency to enter the single crab decision zone compared with crabs in optimal shells, but in the presence of noise this pattern was absent. The weight of the focal crab had no effect on the latency to enter the single zone (Table 2). There was no interaction between sound treatment and shell size and no main effect of sound treatment, shell size or the weight of the focal crab on the latency to enter the group zone (Table 2).

There was a significant three way interaction between sound treatment, shell size and zone on the average proportion of time spent in each zone (Table 2, Fig. 4). Under ambient sound, crabs in suboptimal shells showed no discernible preference for any of the three zones while crabs in optimal shells spent more time with conspecifics; mostly with a single crab. Under ship noise this pattern was reversed. Crabs in a suboptimal shell strongly preferred the zone adjacent to a single crab and spent very little time in the neutral zone whereas for crabs in optimal shells the preference for the zone adjacent to a single crab was reduced under noise and spent their time more evenly in all three zones compared to ambient sound. Crabs in suboptimal shells spent significantly less time 
in the neutral zone than crabs in optimal shells. The weight of the focal crab had no effect on the average proportion of time spent in each zone (Table 2).

305

\section{Discussion}

We predicted, based on the ideas of shell exchange markets and predator dilution, that hermit crabs in suboptimal shells would show a stronger preference for joining groups compared with crabs in optimal shells. Furthermore, we predicted that noise would disrupt this behaviour. Surprisingly, we found the opposite pattern under ambient control, where crabs in suboptimal shells did not show a preference for either zone but crabs in optimal shells preferred to group with a single conspecific. Noise, however, reverses the grouping pattern. While crabs in suboptimal shells now preferred to group with conspecifics and particularly with a single crab, crabs in optimal shells showed no clear preference and spent their time more evenly across all three zones. Thus, although our overarching prediction that noise pollution would disrupt the grouping behaviour of hermit crabs (expressed under ambient conditions) was upheld, the direction of that effect differed from what we expected.

The unexpected pattern under ambient sound that crabs in small shells showed longer latency than crabs in optimal shells might be explained by considering some wider behavioural consequences of shell size. In hermit crabs the latency to emerge from the shell after a short disturbance, also called startle response, is a common measure for boldness (Briffa et al., 2008; Gherardi, Aquiloni, \& Tricarico, 2012). Previous experiments have shown a that hermit crabs in a $100 \%$ optimal shell showed shorter startle response than individuals in $75 \%$ shells (Briffa \& Bibost, 2009). Furthermore, bolder crabs are also more inquisitive and more likely to investigate empty shells compared with shy crabs (Mowles, Cotton \& Briffa, 2012). Thus, the relative lagging of crabs in suboptimal shells to join another individual might be driven by the effect of shell size on inquisitiveness, rather than by the relative costs and benefits of joining a group as we initially hypothesised. Indeed, grouping behaviour has been shown to be influenced by personality (such as 
shy-bold) in a wide range of species (for review see Webster \& Ward, 2011) and gregarious species showed stronger personality differences (von Merten, Zwolak \& Rychlik, 2017).

The grouping pattern we found under ambient sound suggests that shell exchange markets or the dilution effect do not lead to the clusters we observed in P. bernhardus in the wild (S. Tidau, Pers. obs.) and which have been reported in other species (Hazlett, 1966; Hazlett, 1979; Tricarico \& Gherardi, 2006). One factor could be that under ambient sound crabs in suboptimal shells perceived a greater costs from grouping than being solitary. As shown by Briffa and Bibost (2009), crabs in suboptimal shells stay hidden for longer than crabs in optimal shells indicating that they perceive a greater level of risk from conspecifics. Such risk could steam from cannibalism which has occasionally been observed in P. bernhardus (S. Tidau, Pers. obs.) and is also known for other hermit crab species (Tran, O'Grady, Colborn, Van Ness \& Hill, 2014). While some species cluster up to hundreds or thousands (Gherardi, 1991) solitary behaviour has been reported in some species (Hazlett, 1966; Hazlett, 1979) and demonstrated in the field in the long-clawed hermit crab, Pagurus longicarpus, (Tricarico \& Gherardi, 2006). As a consequence of the variety of grouping behaviour across hermit crab species, the clustering and grouping preferences observed in $P$. bernhardus might be species specific. Alternatively, for the baseline behaviour under ambient sound conditions we cannot rule out that our groups (here of two or six crabs) could have been too small to provide predator protection in hermit crabs as predicted due to the 'dilution effect' (Foster \& Treherne, 1981). Indeed, being in small groups might make crabs more apparent to predators than being single. If a predator would detect the group, the crab in a suboptimal shell would be particularly vulnerable to that predator, and if that crab had a smaller apparent body size than other group members, it may be easier to detect due to 'standing out' (Krause \& Godin, 1994).To withdraw into the shell (Gherardi \& Benvenuto, 2001) or flee (Mima, Wada \& Goshima, 2003; Rosen, Schwarz \& Palmer, 2009; Scarratt \& Godin, 1992) thus might be the better strategy to avoid predation by $P$. bernhardus. Finally, we cannot eliminate the possibility that crabs might be attracted by something 
else in the field or driven by abiotic factors such as water currents (Pallas, Garcia-Calvo, Corgos, Bernardez \& Freire, 2006) which opens up questions for further research.

Although the grouping pattern of under ambient sound differed from our initial expectations, it is clear that grouping behaviour is altered by exposure to noise. Indeed, the usual (i.e. under ambient sound) pattern was reversed in the presence of noise. One explanation for why noise reverses decisions about joining a group is that crabs were distracted by the noise so that their ability to make appropriate decisions was impaired leading to the opposite decision made under ambient sound. Thus, crabs in suboptimal shells that would normally behave cautiously fail to adjust their behaviour to match the size of their shell in the presence of noise i.e. crabs in suboptimal shells showed more cautious behaviour by having longer latency to encounter a single conspecific. This distraction effect of noise on crustaceans has been observed under predation risk (Chan et al., 2010) and suggested as a mechanism to explain behavioural changes in other taxa under noise (Simpson et al., 2015). An alternative explanation is that crabs exposed to noise might have perceived the noise itself as a threat. Besides functioning as a novel and unpredictable stimulus for animals, some sound properties of noise could also be biologically similar to relevant stimuli i.e. elicit similar responses (Francis \& Barber, 2013; Shannon et al., 2016). For instance, the Blainville's beaked whales, Mesoplodon densirostris, responded in similar ways to simulated military sonar and to playbacks of predatory killer whale, Orcinus orca, calls (Tyack et al., 2011). In this case, crabs in suboptimal shells may have weighed the potential benefits of associating with another crab (e.g. the dilution effects) higher than the costs (e.g. attacks by other hermit crabs). Under acute predation threat, animals are expected to join larger shoals (e.g. Hager \& Helfman, 1991). Here crabs that were both exposed to noise and supplied with suboptimal shells (and were therefore at a high risk of predation) chose to avoid the neutral zone. The current data do not allow us to distinguish between these two possibilities (distraction and perception of threat) directly. However, we note that crabs in optimal shells also changed their preference i.e. associating with another individual was reduced under ship noise compared with ambient noise. That implies that noise disrupted the usual decision-making 
process in both groups, crabs in suboptimal and optimal shells alike. Furthermore, the size of the shell does not seem to protect from the impacts of noise.

Our data add to the growing body of evidence that anthropogenic noise can clearly influence group dynamics from mammals to crustaceans. As noted above, the direction, intensity and consequences for survival and fitness are far less obvious. Groups of Mediterranean spiny lobsters, P. elepha, (Filiciotto et al., 2014), European sea bass, D. labrax, (when exposed to pile-driving, Herbert-Read et al., 2017), bottlenose dolphins, T. truncatus, (Bas et al., 2017) and red swamp crayfish, P. clarkii, (Celi et al., 2013) were less cohesive, decreases cooperative interactions among conspecifics and cichlid fish, Neolamprologus pulcher, even more aggressive (Bruintjes \& Radford, 2013). On the other hand, in the trevally P. dentex (Fewtrell \& McCauley, 2012), the European sea bass $D$. labrax (when exposed to ship noise, Neo et al., 2018), the Carolina chickadees, $P$. carolinensis, and tufted titmice, B. bicolor, (Owens et al., 2012) shoals respectively flocks formed tighter groups under anthropogenic noise. These effects could be due to stress and distraction of attention, stimulus perception and filtering or combination of these mechanisms. Since an animal's attention to perceive and process stimuli is limited (Dukas, 2004) and since noise and other pollutants have been shown to affect animals across sensory channels (Halfwerk \& Slabbekoorn, 2015), it has been suggested that anthropogenic noise acts as a distracting stimulus (Chan et al., 2010; Simpson et al., 2015).

Our study is one of few which looked at cross-modal effects of anthropogenic noise on grouping behaviour and shows that this occurs in hermit crabs. Specifically, in P. bernhardus, exposure to ship noise causes crabs that occupy suboptimal resource units (a shell that is too small) to behave as if they possessed an optimal resource unit in terms of their interactions with other individuals. Further work will be warranted to investigate the underlying causes of the behavioural changes (for example lack of caution or risk avoidance). Nevertheless, given that survival in hermit crabs is strongly tied to the quality of their gastropod shell, any changes to shell-mediated behaviour could impact individual survival and hence population structure. Grouping behaviour is a common 

be further investigated. 
407

408

409

410

411

412

413

414

415

416

417

418

419

420

421

422

423

424

425

426

427

428

429

430

\section{References}

Angel, J. E. (2000). Effects of shell fit on the biology of the hermit crab Pagurus longicarpus (Say). Journal of Experimental Marine Biology and Ecology, 243, 169-184.

Audacity Team. (2017). Audacity(R): Free Audio Editor and Recorder [Computer application]. Version 2.2.1. Retrieved from https://audacityteam.org/

Bas, A. A., Christiansen, F., Öztürk, B., Öztürk, A. A., Erdoğan, M. A., \& Watson, L. J. (2017). Marine vessels alter the behaviour of bottlenose dolphins Tursiops truncatus in the Istanbul Strait, Turkey. Endangered Species Research, 34, 1-14.

Bates, D., Mächler, M., Bolker, B., \& Walker, S. (2015). Fitting Linear Mixed-Effects Models using Ime4. Journal of Statistical Software, 67, 1-48.

Bazazi, S., Pfennig, K. S., Handegard, N. O., \& Couzin, I. D. (2012). Vortex formation and foraging in polyphenic spadefoot toad tadpoles. Behavioral Ecology and Sociobiology, 66, 879-889.

Bertness, M. D. (1981a). The influence of shell-type on hermit crab growth rate and clutch size (Decapoda, Anomura). Crustaceana, 40, 197-205.

Bertness, M. D. (1981b). Predation, physical stress, and the organization of a tropical rocky intertidal hermit crab community. Ecology, 62, 411-425.

Breithaupt, T. (2002). Sound Perception in Aquatic Crustaceans. In K. Wiese (Ed.), The Crustacean Nervous System (pp. 548-558). Berlin, Heidelberg: Springer.

Briffa, M. (2013). The influence of personality on a group level process: Shy hermit crabs make longer vacancy chains. Ethology, 119, 1014-1023.

Briffa, M., \& Bibost, A.-L. (2009). Effects of shell size on behavioural consistency and flexibility in hermit crabs. Canadian Journal of Zoology, 87, 597-603.

Briffa, M., \& Elwood, R. W. (2007). Monoamines and decision making during contests in the hermit crab Pagurus bernhardus. Animal Behaviour, 73, 605-612. 
Briffa, M., Rundle, S. D., \& Fryer, A. (2008). Comparing the strength of behavioural plasticity and consistency across situations: Animal personalities in the hermit crab Pagurus bernhardus. Proceedings of the Royal Society B-Biological Sciences, 275, 1305-1311.

Bruintjes, R., \& Radford, A. N. (2013). Context-dependent impacts of anthropogenic noise on individual and social behaviour in a cooperatively breeding fish. Animal Behaviour, 85, 13431349.

Brumm, H. (2004). The impact of environmental noise on song amplitude in a territorial bird. Journal of Animal Ecology, 73, 434-440.

Brumm, H., \& Slabbekoorn, H. (2005). Acoustic communication in noise. In P. J. B. Slater, C. T. Snowdon, H. J. Brockmann, T. J. Roper, \& M. Naguib (Eds.), Advances in the Study of Behavior (Vol. 35, pp. 151-209). San Diego: Elsevier Academic Press Inc.

Budelmann, B. U. (1992). Hearing in crustacea. In D. B. Webster, A. N. Popper, \& R. R. Fay (Eds.), The Evolutionary Biology of Hearing (pp. 131-139). New York: Springer.

Celi, M., Filiciotto, F., Parrinello, D., Buscaino, G., Damiano, M. A., Cuttitta, A., . . Vazzana, M. (2013). Physiological and agonistic behavioural response of Procambarus clarkii to an acoustic stimulus. Journal of Experimental Biology, 216, 709-718.

Chan, A. A. Y.-H., Giraldo-Perez, P., Smith, S., \& Blumstein, D. T. (2010). Anthropogenic noise affects risk assessment and attention: The distracted prey hypothesis. Biology Letters, 6, 458-461.

Childress, M. J., \& Herrnkind, W. F. (2001). The guide effect influence on the gregariousness of juvenile Caribbean spiny lobsters. Animal Behaviour, 62, 465-472.

Clark, C. W., Ellison, W. T., Southall, B. L., Hatch, L., Van Parijs, S. M., Frankel, A., \& Ponirakis, D. (2009). Acoustic masking in marine ecosystems: Intuitions, analysis, and implication. Marine Ecology Progress Series, 395, 201-222.

Codarin, A., Wysocki, L. E., Ladich, F., \& Picciulin, M. (2009). Effects of ambient and boat noise on hearing and communication in three fish species living in a marine protected area (Miramare, Italy). Marine Pollution Bulletin, 58, 1880-1887. 
Côté, I. M., \& Poulinb, R. (1995). Parasitism and group size in social animals: A meta-analysis. Behavioral Ecology, 6, 159-165.

Curé, C., Antunes, R., Alves, A. C., Visser, F., Kvadsheim, P. H., \& Miller, P. J. O. (2013). Responses of male sperm whales (Physeter macrocephalus) to killer whale sounds: Implications for antipredator strategies. Scientific Reports, 3, 1579.

Daviews, C. R., Ayres, J. M., Dye, C., \& Deane, L. M. (1991). Malaria infection rate of amazonian primates increases with body weight and group size. Functional Ecology, 5, 655-662.

Dukas, R. (2004). Causes and consequences of limited attention. Brain Behavior and Evolution, 63, 197-210.

Elwood, R. W., \& Neil, S. J. (1992). Assessments and Decisions: A Study of Information gathering by Hermit Crabs. London; New York: Chapman \& Hall.

Erbe, C., Reichmuth, C., Cunningham, K., Lucke, K., \& Dooling, R. (2016). Communication masking in marine mammals: A review and research strategy. Marine Pollution Bulletin, 103, 15-38.

Evans, S. R., Finnie, M., \& Manica, A. (2007). Shoaling preferences in decapod crustacea. Animal Behaviour, 74, 1691-1696.

Fewtrell, J. L., \& McCauley, R. D. (2012). Impact of air gun noise on the behaviour of marine fish and squid. Marine Pollution Bulletin, 64, 984-993.

Filiciotto, F., Vazzana, M., Celi, M., Maccarrone, V., Ceraulo, M., Buffa, G., Di Stefano, V., . . Buscaino, G. (2014). Behavioural and biochemical stress responses of Palinurus elephas after exposure to boat noise pollution in tank. Marine Pollution Bulletin, 84, 104-114.

Foster, W. A., \& Treherne, J. E. (1981). Evidence for the dilution effect in the selfish herd from fish predation on a marine insect. Nature, 293, 466.

Francis, C. D., \& Barber, J. R. (2013). A framework for understanding noise impacts on wildlife: An urgent conservation priority. Frontiers in Ecology and the Environment, 11, 305-313.

Gherardi, F. (1991). Relative growth, population structure, and shell-utilization of the hermit crab Clibanarius erythropus in the Mediterranean. Oebalia, 17, 181-196. 
Gherardi, F., Aquiloni, L., \& Tricarico, E. (2012). Behavioral plasticity, behavioral syndromes and animal personality in crustacean decapods: An imperfect map is better than no map. Current Zoology, 58, 567-579.

Gherardi, F., \& Benvenuto, C. (2001). Clustering behaviour in a mediterranean population of the hermit crab, Clibanarius erythropus. Ophelia, 55, 1-10.

Gherardi, F., \& Vannini, M. (1993). Hermit crabs in a mangrove swamp: Proximate and ultimate factors in the clustering of Clibanarius laevimanus. Journal of Experimental Marine Biology and Ecology, 168, 167-187.

Hager, M. C., \& Helfman, G. S. (1991). Safety in numbers: Shoal size choice by minnows under predatory threat. Behavioral Ecology and Sociobiology, 29, 271-276.

Halfwerk, W., \& Slabbekoorn, H. (2015). Pollution going multimodal: The complex impact of the human-altered sensory environment on animal perception and performance. Biology Letters, 11, 20141051.

Hasan, M. R., Crane, A. L., Ferrari, M. C. O., \& Chivers, D. P. (2018). A cross-modal effect of noise: The disappearance of the alarm reaction of a freshwater fish. Animal Cognition, 21, 419-424.

Hazlett, B. A. (1966). Social behavior of the Paguridae and Diogenidae of Curaçao. Studies on the Fauna of Curaçao and other Caribbean Islands, 23, 1-143.

Hazlett, B. A. (1978). Shell exchanges in hermit crabs - aggression, negotiation, or both. Animal Behaviour, 26, 1278-1279.

Hazlett, B. A. (1979). 'Individual distance in crustacea: IV. Distance and dominance hierarchies in Pagurus pollicaris'. Marine Behaviour and Physiology, 6, 225-242.

Hazlett, B. A. (2015). Social Recognition in Hermit Crabs. In L. Aquiloni, \& E. Tricarico (Eds.), Social Recognition in Invertebrates: The Knowns and the Unknowns (pp. 49-56). Cham: Springer International Publishing.

Hazlett, B. A., \& Herrnkind, W. (1980). Orientation to shell events by the hermit crab Clibanarius vittatus (BOSC) (Decapoda, Paguridea). Crustaceana, 39, 311-314. 
Herbert-Read, J. E., Kremer, L., Bruintjes, R., Radford, A. N., \& loannou, C. C. (2017). Anthropogenic noise pollution from pile-driving disrupts the structure and dynamics of fish shoals. Proceedings of the Royal Society B: Biological Sciences, 284, 20171627.

Kight, C. R., \& Swaddle, J. P. (2011). How and why environmental noise impacts animals: An integrative, mechanistic review. Ecology Letters, 14, 1052-1061.

Krause, J., \& Godin, J.-G. J. (1994). Shoal choice in the banded killifish (Fundulus diaphanus, Teleostei, Cyprinodontidae): Effects of predation risk, fish size, species composition and size of shoals. Ethology, 98, 128-136.

Krause, J., \& Ruxton, G. D. (2002). Living in Groups. Oxford: Oxford University Press.

Kunc, H. P., Lyons, G. N., Sigwart, J. D., McLaughlin, K. E., \& Houghton, J. D. R. (2014). Anthropogenic noise affects behavior across sensory modalities. American Naturalist, 184, E93-E100.

Lovell, J. M., Findlay, M. M., Moate, R. M., \& Yan, H. Y. (2005). The hearing abilities of the prawn Palaemon serratus. Comparative Biochemistry and Physiology Part A: Molecular \& Integrative Physiology, 140, 89-100.

Luo, J. H., Siemers, B. M., \& Koselj, K. (2015). How anthropogenic noise affects foraging. Global Change Biology, 21, 3278-3289.

Lürling, M., \& Scheffer, M. (2007). Info-disruption: Pollution and the transfer of chemical information between organisms. Trends in Ecology \& Evolution, 22, 374-379.

The MathWorks, Inc. (2015). MATLAB and Statistics Toolbox Release 2015b. Natick: USA.

Maxwell, R. J., Zolderdo, A. J., Bruijn, R., Brownscombe, J. W., Staaterman, E., Gallagher, A. J., \& Cooke, S. J. (2018). Does motor noise from recreational boats alter parental care behaviour of a nesting freshwater fish? Aquatic Conservation: Marine and Freshwater Ecosystems, 28, 969-978.

McCormick, M. I., Allan, B. J. M., Harding, H., \& Simpson, S. D. (2018). Boat noise impacts risk assessment in a coral reef fish but effects depend on engine type. Scientific Reports, 8, 3847. 
Merchant, N. D., Fristrup, K. M., Johnson, M. P., Tyack, P. L., Witt, M. J., Blondel, P., \& Parks, S. E. (2015). Measuring acoustic habitats. Methods in Ecology and Evolution, 6, 257-265.

Mima, A., Wada, S., \& Goshima, S. (2003). Antipredator defence of the hermit crab Pagurus filholi induced by predatory crabs. Oikos, 102, 104-110.

Mooring, M. S., Fitzpatrick, T. A., Nishihira, T. T., Reisig, D. D., \& Hall (2004). Vigilance, predation risk, and the allee effect in desert bighorn sheep. Journal of Wildlife Management, 68, 519-532.

Mowles, S. L., Cotton, P. A., \& Briffa, M. (2012). Consistent crustaceans: The identification of stable behavioural syndromes in hermit crabs. Behavioral Ecology and Sociobiology, 66, 10871094.

Nedelec, S. L., Radford, A. N., Pearl, L., Nedelec, B., McCormick, M. I., Meekan, M. G., \& Simpson, S. D. (2017). Motorboat noise impacts parental behaviour and offspring survival in a reef fish. Proceedings of the Royal Society B-Biological Sciences, 284, 20170143.

Neo, Y. Y., Hubert, J., Bolle, L. J., Winter, H. V., \& Slabbekoorn, H. (2018). European seabass respond more strongly to noise exposure at night and habituate over repeated trials of sound exposure. Environmental Pollution, 239, 367-374.

Owens, J. L., Stec, C. L., \& O'Hatnick, A. (2012). The effects of extended exposure to traffic noise on parid social and risk-taking behavior. Behavioural Processes, 91, 61-69.

Pallas, A., Garcia-Calvo, B., Corgos, A., Bernardez, C., \& Freire, J. (2006). Distribution and habitat use patterns of benthic decapod crustaceans in shallow waters: A comparative approach. Marine Ecology Progress Series, 324, 173-184.

Pine, M. K., Jeffs, A. G., \& Radford, C. A. (2012). Turbine sound may influence the metamorphosis behaviour of estuarine crab megalopae. PLOS ONE, 7, e51790.

Popper, A. N., Salmon, M., \& Horch, W. K. (2001). Acoustic detection and communication by decapod crustaceans. Journal of Comparative Physiology A, 187, 83-89.

Powell, G. V. N. (1974). Experimental analysis of the social value of flocking by starlings (Sturnus vulgaris) in relation to predation and foraging. Animal Behaviour, 22, 501-505. 
R Core Team. (2017). A language and environment for statistical computing. Vienna: Austria: R Foundation for Statistical Computing. Retrieved from: https://www.r-project.org/

Ratchford, S. G., \& Eggleston, D. B. (1998). Size- and scale-dependent chemical attraction contribute to an ontogenetic shift in sociality. Animal Behaviour, 56, 1027-1034.

Rieucau, G., \& Giraldeau, L.-A. (2009). Group size effect caused by food competition in nutmeg mannikins (Lonchura punctulata). Behavioral Ecology, 20, 421-425.

Roberts, L., Cheesman, S., Elliott, M., \& Breithaupt, T. (2016). Sensitivity of Pagurus bernhardus (L.) to substrate-borne vibration and anthropogenic noise. Journal of Experimental Marine Biology and Ecology, 474, 185-194.

Rogers, P. H., Hawkins, A. D., Popper, A. N., Fay, R. R., \& Gray, M. D. (2016). Parvulescu Revisited: Small Tank Acoustics for Bioacousticians. In N. A. Popper, \& A. Hawkins (Eds.), The Effects of Noise on Aquatic Life II (pp. 1041-1048). New York: Springer.

Rosen, E., Schwarz, B., \& Palmer, A. R. (2009). Smelling the difference: Hermit crab responses to predatory and nonpredatory crabs. Animal Behaviour, 78, 691-695.

Sara, G., Dean, J. M., D'Amato, D., Buscaino, G., Oliveri, A., Genovese, S., Ferro, S., Buffa, G., Lo Martire, M., \& Mazzola, S. (2007). Effect of boat noise on the behaviour of bluefin tuna Thunnus thynnus in the Mediterranean Sea. Marine Ecology Progress Series, 331, 243-253.

Scarratt, A. M., \& Godin, J.-G. J. (1992). Foraging and antipredator decisions in the hermit crab Pagurus acadianus (Benedict). Journal of Experimental Marine Biology and Ecology, 156, 225-238.

Shafiei Sabet, S., Neo, Y. Y., \& Slabbekoorn, H. (2015). The effect of temporal variation in sound exposure on swimming and foraging behaviour of captive zebrafish. Animal Behaviour, 107, 49-60.

Shafiei Sabet, S., Van Dooren, D., \& Slabbekoorn, H. (2016). Son et lumiere: Sound and light effects on spatial distribution and swimming behavior in captive zebrafish. Environmental Pollution, $212,480-488$. 
Shannon, G., McKenna, M. F., Angeloni, L. M., Crooks, K. R., Fristrup, K. M., Brown, E., Warner, K. A., ... Wittemyer, G. (2016). A synthesis of two decades of research documenting the effects of noise on wildlife. Biological Reviews, 91, 982-1005.

Siemers, B. M., \& Schaub, A. (2011). Hunting at the highway: Traffic noise reduces foraging efficiency in acoustic predators. Proceedings of the Royal Society B-Biological Sciences, 278, 16461652.

Sih, A., Ferrari, M. C. O., \& Harris, D. J. (2011). Evolution and behavioural responses to humaninduced rapid environmental change. Evolutionary Applications, 4, 367-387.

Simpson, S. D., Purser, J., \& Radford, A. N. (2015). Anthropogenic noise compromises antipredator behaviour in European eels. Global Change Biology, 21, 586-593.

Simpson, S. D., Radford, A. N., Holles, S., Ferarri, M. C. O., Chivers, D. P., McCormick, M. I., \& Meekan, M. G. (2016a). Small-boat noise impacts natural settlement behavior of coral reef fish larvae. In N. A. Popper, \& A. Hawkins (Eds.), The Effects of Noise on Aquatic Life II (pp. 1041-1048). New York: Springer.

Simpson, S. D., Radford, A. N., Nedelec, S. L., Ferrari, M. C. O., Chivers, D. P., McCormick, M. I., \& Meekan, M. G. (2016b). Anthropogenic noise increases fish mortality by predation. Nature Communication, 7, e10544.

Sun, J. W. C., \& Narins, P. M. (2005). Anthropogenic sounds differentially affect amphibian call rate. Biological Conservation, 121, 419-427.

Talsma, D., Senkowski, D., Soto-Faraco, S., \& Woldorff, M. G. (2010). The multifaceted interplay between attention and multisensory integration. Trends in Cognitive Sciences, 14, 400-410. Taylor, P. R. (1981). Hermit crab fitness: The effect of shell condition and behavioral adaptations on environmental resistance. Journal of Experimental Marine Biology and Ecology, 52, 205-218.

Tran, M. V., O'Grady, M., Colborn, J., Van Ness, K., \& Hill, R. W. (2014). Aggression and food resource competition between sympatric hermit crab species. PLOS ONE, 9, e91823. 
Tricarico, E., \& Gherardi, F. (2006). Shell acquisition by hermit crabs: Which tactic is more efficient? Behavioral Ecology and Sociobiology, 60, 492-500.

Tuomainen, U., \& Candolin, U. (2011). Behavioural responses to human-induced environmental change. Biological Reviews, 86, 640-657.

Tyack, P. L., Zimmer, W. M. X., Moretti, D., Southall, B. L., Claridge, D. E., Durban, J. W., . . Boyd, I. L. (2011). Beaked Whales Respond to Simulated and Actual Navy Sonar. PLOS ONE, 6, e17009.

Vance, R. R. (1972). The role of shell adequacy in behavioral interactions involving hermit crabs. Ecology, 53, 1075-1083.

von Merten, S., Zwolak, R., \& Rychlik, L. (2017). Social personality: A more social shrew species exhibits stronger differences in personality types. Animal Behaviour, 127, 125-134.

Wale, M. A., Simpson, S. D. \& Radford, A. N. (2013). Noise negatively affects foraging and antipredator behaviour in shore crabs. Animal Behaviour, 86, 111-118.

Ward, A. J. W., Herbert-Read, J. E., Sumpter, D. J. T., \& Krause, J. (2011). Fast and accurate decisions through collective vigilance in fish shoals. Proceedings of the National Academy of Sciences of the United States of America, 108, 2312-2315.

Webster, M. M., \& Ward, A. J. W. (2011). Personality and social context. Biological Reviews, 86, 759773.

Wilson, D. (2009). Causes and Benefits of Chick Aggregations in Penguins. The Auk, 126, 688-693.

Wisniewska, D. M., Johnson, M., Teilmann, J., Siebert, U., Galatius, A., Dietz, R., \& Madsen, P. T. (2018). High rates of vessel noise disrupt foraging in wild harbour porpoises Phocoena phocoena. Proceedings of the Royal Society B: Biological Sciences, 285, 20172314.

Young, A. M. (1978). Desiccation tolerances for three hermit crab species Clibanarius vittatus (Bosc), Pagurus pollicaris Say and P. longicarpus Say (Decapoda, Anomura) in the North Inlet Estuary, South Carolina, U.S.A. Estuarine and Coastal Marine Science, 6, 117-122. 
636 Table 1 The orthogonal design of the interaction between sound treatment and occupied shell.

\begin{tabular}{llll}
\hline$n=45$ & & \multicolumn{2}{c}{ Sound treatment } \\
Initially occupied shell & $75 \%$ (suboptimal) & $n=9$ & Ambient control \\
& $100 \%$ (optimal) & $n=11$ & $n=10$ \\
& & $n=15$
\end{tabular}

637 The values in each cell of the table indicate the proportion of preferred shell weight of shells

638 supplied to crabs in each group prior to observations.

639

640 Table 2 Summay of results mixed effects models (GLMM and LMM) used to determine the effects of 641 predictors on meausures grouping behaviour.

\begin{tabular}{lll}
\hline Variable & $\chi^{2}$ & $\mathrm{P}$ \\
\hline Entering the single zone & & \\
$\quad$ Sound treatment ${ }^{*}$ shell size & 1.27 & 0.26 \\
$\quad$ Sound treatment & 0.003 & 0.96 \\
Shell size & 1.25 & 0.26 \\
$\quad$ Crab weight & 2.5 & 0.11 \\
Entering the group zone & & \\
$\quad$ Sound treatment * shell size & 0.06 & 0.81 \\
$\quad$ Sound treatment & 0.03 & 0.87 \\
Shell size & 1.04 & 0.31 \\
Crab weight & 0.13 & 0.72 \\
Latency to enter the single zone & & \\
Sound treatment * shell size & 5.6 & $\mathbf{0 . 0 1 8}$ \\
Crab weight & 2.0 & 0.16 \\
Latency to enter the group zone & & \\
$\quad$ Sound treatment * shell size & 0.4 & 0.55 \\
Sound treatment & 0.06 & 0.81 \\
Shell size & 2.45 & 0.11 \\
Crab weight & 0.8 & 0.38 \\
Average proportion of time spent in each zone & & \\
$\quad$ Sound treatment * shell size * zones & 7.1 & $\mathbf{0 . 0 2 8}$ \\
Crab weight & 0.4 & 0.51 \\
\hline
\end{tabular}

642 Note that results were obtained using a model simplification approach, and as such reporting is

643 restricted to the highest order effects, where significant interactions are present. 


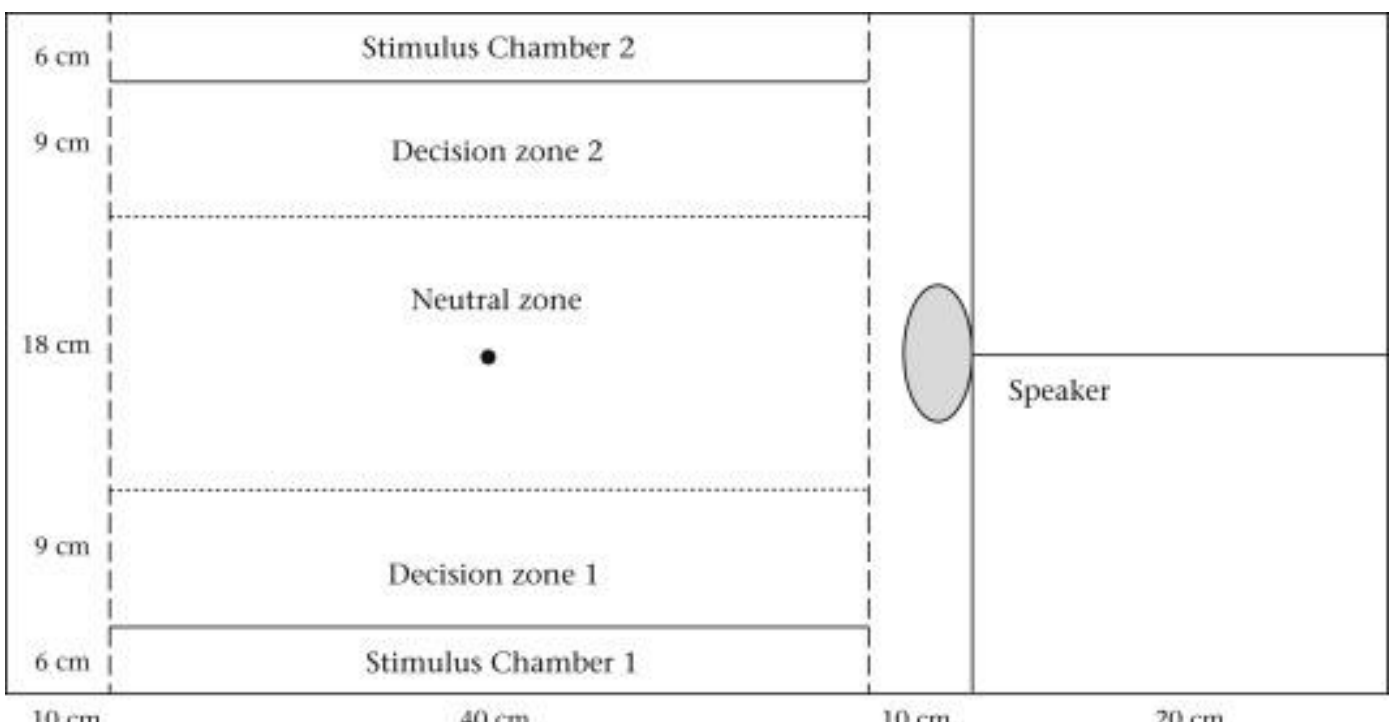

Figure 1. Tank set-up and observation arena. Thick solid lines represent the tank walls and speaker supports, the dashed lines represent the mesh separating the arena from the rest of the tank, the tin solid lines show the walls of the stimulus chambers and the dotted lines show the decision zones marked at the bottom of the tank.

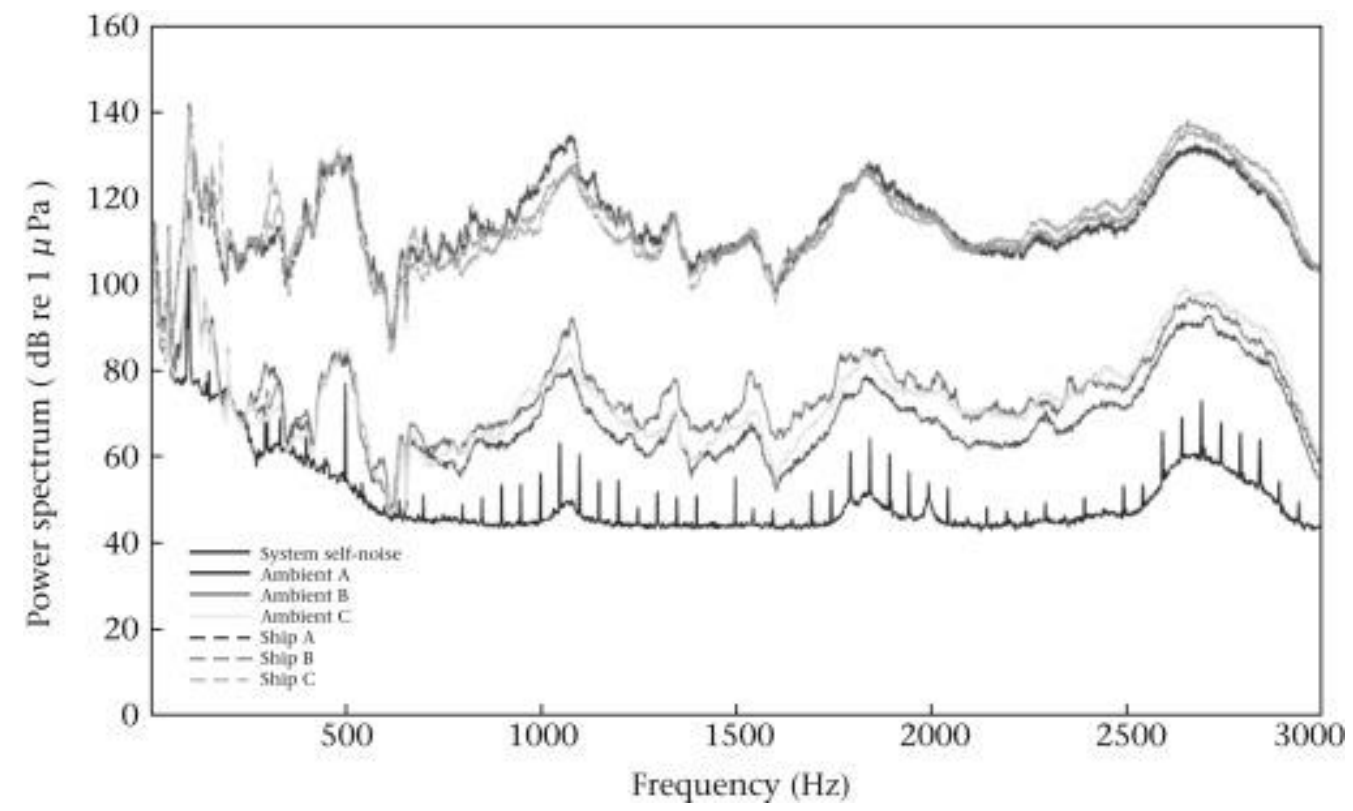

Figure 2. Power spectrum analysis for 3 ship noise playbacks and 3 corresponding ambient sound playbacks. The system's self noise characterises the sound output by the equipment without playbacks. 


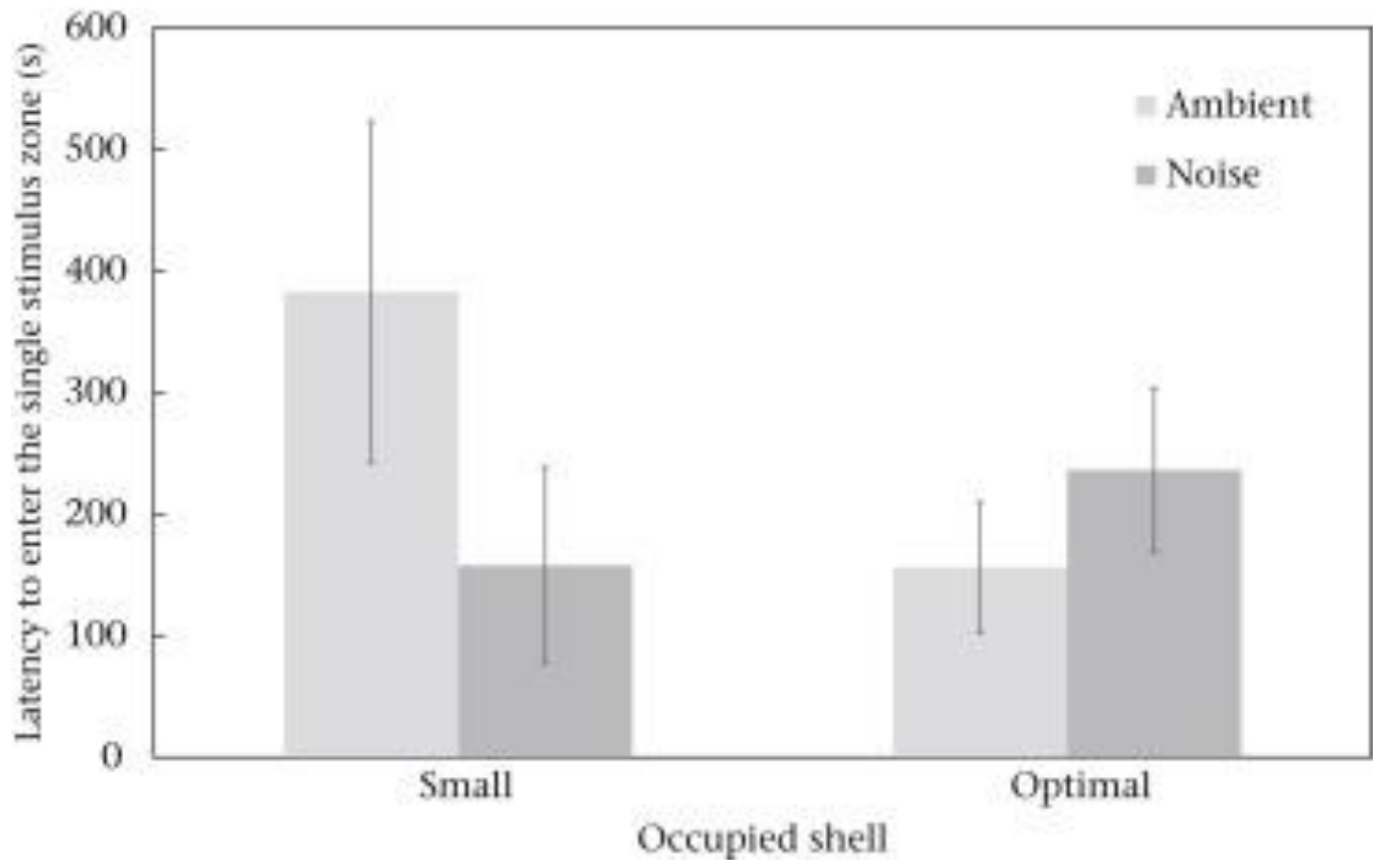

657 Figure 3. The interaction effect between sound treatment and shell size on the latency to enter the single stimulus zone. 658 Error bars show standard error.

659

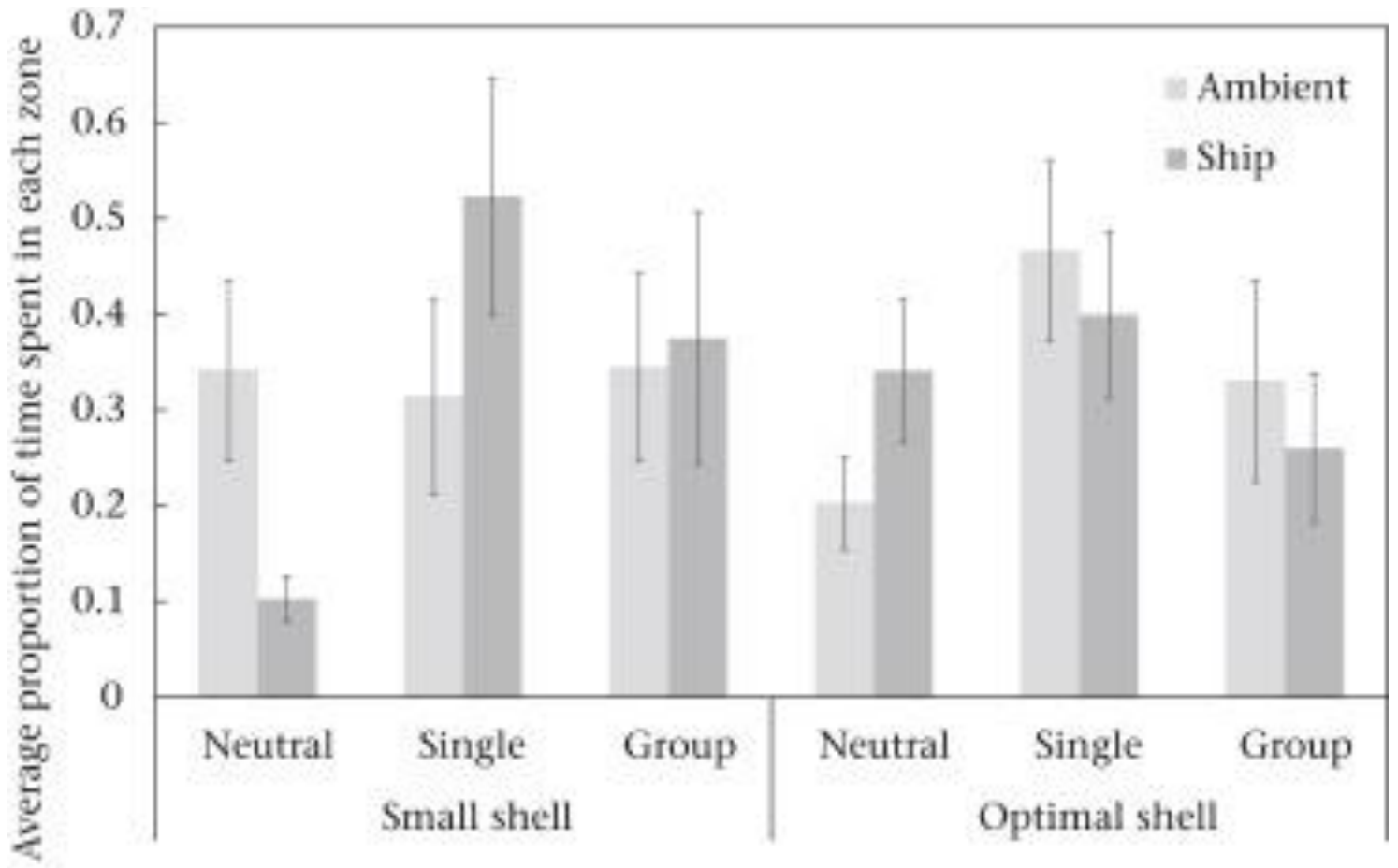

Shell size $x$ zone

Figure 4. Proportion of time (out of a maximum of $20 \mathrm{~min}$ ) spent in each of the three zones under ambient sound and ship 663 noise. Error bars show standard errors. 